\title{
Visual Impact of Graphic Information in the Package
}

\author{
Petra Balaban-Đurđev and Varvara Maletić \\ The Higher Technical School of Professional Education, \\ Novi Sad, Serbia
}

balaban@vtsns.edu.rs varvara ns@yahoo.com

\begin{abstract}
This paper aims to, on the basis of literature on this subject and our own research, point to the significance of the package design as a medium through which information is conveyed and to its importance for the process of communication with the consumer.

The basic visual effects in form of information that are used in the package design and that enable the manipulation of the consumer are text, picture and color.

Finally, according to the analysis of the concrete example of the chosen package, the paper provides a conclusion regarding the influence and significance of the package as a visual communication medium.
\end{abstract}

Keywords: visual communication, package, graphic information

\section{Introduction}

As it is a well-known fact, one of the important goals of the package is to communicate its content, i.e. to make a product as close to the immediate consumer as possible (Fruht, 1992).

The basic elements of this communication are text, picture, color, shape and material of the package.

It could be said that the package is a typical example of the visual communication that represents every conveying of information through visual signs, symbols, text, drawings and pictures and thus provides communication with social environment building up connections with the audience, i.e. the target group (Hembree, 2008).

It is assumed that depending on the type of a product and information source in the package, between $2 / 3$ and $3 / 4$ of consumers make decision to purchase it at the Point of Presentation (Bihler, 2005). According to the same author, some product captivates consumers' attention just in a couple of seconds. Within such a short period of time the package (as a medium) should send a message that motivates a consumer to buy it.

Material published as part of this publication, either on-line or in print, is copyrighted by the Informing Science Institute. Permission to make digital or paper copy of part or all of these works for personal or classroom use is granted without fee provided that the copies are not made or distributed for profit or commercial advantage AND that copies 1) bear this notice in full and 2) give the full citation on the first page. It is permissible to abstract these works so long as credit is given. To copy in all other cases or to republish or to post on a server or to redistribute to lists requires specific permission and payment of a fee. Contact Publisher@InformingScience.org to request redistribution permission.
The first part of this paper provides an overview of goals and designs of the package but only within the framework of the paper topic - visual impact of graphic design of a particular product (biscuits).

In the second part of the paper the impact of the visual graphic information of the package is researched by means of a questionnaire. 


\section{The Package Design as an Element of Communication}

Until recently, the package had a general purpose of holding a product, then having it preserved and transported from the point of production to the point of consumption.

Today, the package also has to meet the requirements concerning product protection and providing of information, but in the modern society the package is of considerable importance as a marketing tool and as an integral part of a trademark identity (brand).

It has to sell the goods by itself, especially when faced with fierce competition from numerous products. A product offers itself by its attractive package and overall artistic and graphic presentation. The package makes, as it were, a personal contact and creates a certain psychological effect on an individual. It is the package that arouses emotions and motivates purchase when one is holding a product examining and evaluating it. At such moments, a wish and decision are made.

The package design could be considered from two points of view - regarding the designing of the package itself and regarding information (Jurečić, 2004).

The main task of graphic designing is to have these two aspects united and harmonized. In addition to indirect communication between a producer and consumer, every package designer is an active creator of a direct communication between a product and consumer.

What is meant in terms of communication is the process of sending, receiving and using information.

In order to establish an efficient visual communication, there has to be a message sender and also a message receiver such as the audience. The designer decodes visual messages by transferring the sender's needs in pictures and content which make it easy for the receiver to connect with, (see Figure 1).

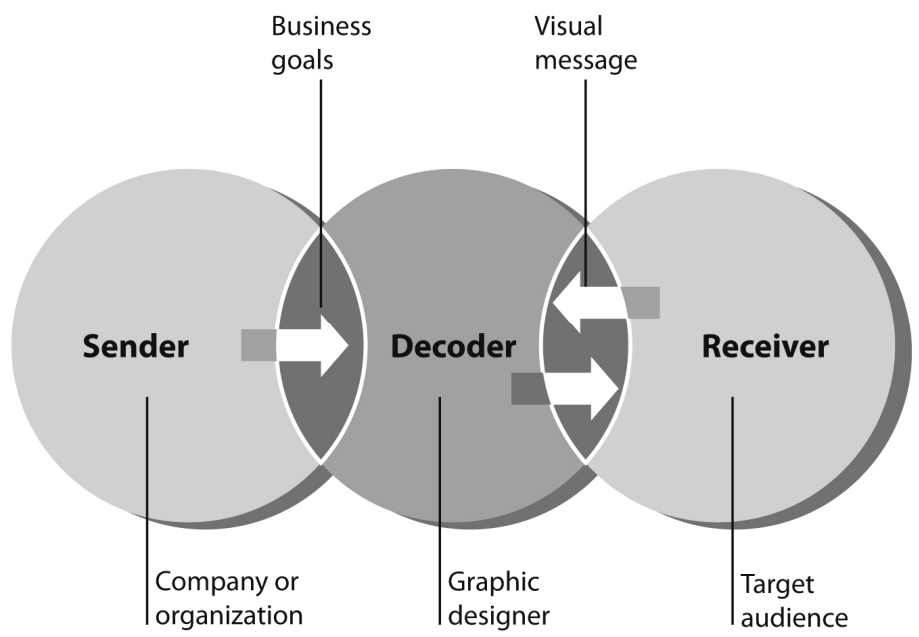

Figure 1. Visual communication (Hembree, 2008)

The task of a graphic designer is to make a message as attractive as possible, so that the one for whom it is intended pays attention to it. The message has to be readable and intelligible, clear and distinct so that we can understand it, and it also has to be designed in such a way to have a positive effect on us. 
The fundamental requirements and tasks that a quality package design has to fulfill are (Fruht, 1992):

- protection of a product that is packaged from mechanical damage, climate changes, losing flavor or form, from the impact of other flavors, from microorganisms etc.;

- functionality - easy manipulation, i.e. user-friendliness;

- adaptation to requirements of the modern industrial production and mass consumption;

- quality artistic and aesthetic making.

Special requirements that graphic design of a package is to satisfy are:

- clear identification of a product (using the sign and logo or characteristic colors);

- harmonious choice of characters and fonts of a text and letters which should be readable at a normal distance and without additional effort;

- harmony of colors, text and illustrations.

The text should contain the following, basic data: the name of the product (visible at several places depending on the package shape), name and address of the producer, the names of the components of the product that is packaged (important for foodstuff), weight, dimension and quantity, warning concerning the use, dose, guaranteed shelf life, instructions for use.

\section{The Basic Elements of Package Communication}

\section{a) Text}

Successful understanding between a sender (the package) and receiver (the consumer) depends on the implementation of the mutual structure of organization of signs, i.e. the mutual code - the typography alphabet (Jurečić, 2004). The fundamental task concerning the use of text in the package is the ranking of the text according to the importance and necessity; also, simplicity should be kept along with shortness because any kind of the excessive use of textual effects just reduces the clarity and thus interferes with understanding and readability.

\section{b) Pictorial Information}

Apart from paying attention to product quality and usability, consumers enjoy the package design of the product when purchasing commodities.

According to some research, it has been pointed out that using an illustration in the package design can draw more attention to the product and that having illustrations in the package design is one of the factors which influences buying emotion (Wang \& Chen, 2007).

An illustration could be realistic, a true copy of the reality or stylized. It could be a photograph or a drawing of the product.

A picture or drawing of the product used in the package provides the viewer with information about the packaged product.

Symbols are signs that mark some real thing or an abstract notion.

A logo or a trademark is a symbol representing the image and notion that is built up in people who get in touch with a particular company. Corporate identity and a logo are visual presentations of a company that symbolize the producer and its commodities, so that they could be distin- 
guished from similar products of other producers. A logo has to be functional and easy to remember.

\section{c) Colors}

Surveying the available literature on this subject it could be concluded that regarding the use of color in the package design, especially for the foodstuff, following information is important:

- Brand identification

- Product color identification

- Impact on the consumer disposition

- Impact on the feeling of the product when it is consumed

- In order to arouse the feeling of ease, comfort and happiness in consumers, bright colors should be used; to suggest seriousness - darker colors; to suggest diet and light products - white or light colors; to suggest healthy and natural products - green color should be used;

- According to (Perović, 2001) colors that stimulate appetite are for example: orange, intense red and light green; green evokes the feeling of health, orange and red imply vividness and sociability, blue suggests freshness and cleanliness especially when combined with white.

Depending on the type of a product and its purpose, the choice of colors should be taken into account because a wrong choice could convey a wrong message to the consumer who would not make a choice in favor of that product. Natural characteristics of elements found in the nature and long human experience have proved that human mind reacts to particular colours while products whose package is the subject of this paper evoke certain feelings and associations that contribute to the consumer's attitude about buying that product. It has been proved that warm colors are first to be noticed; color might influence how one perceives the size or quality of a particular product. Thus, for example, if the package of the same product is of the same shape but in different colors, the consumer will have different opinion regarding the product weight (the lightest products are in white color, heavier products are those in yellow and green colors of the package, while those packaged in red or black color are the heaviest according to the respondents). Depending on the type of a product, the color should be taken into account. There are numerous research into that subject and the conclusion they provide is that the color of the package creates the impression of taste (yellow and green come with sour, warm tones of yellow, orange and red are connected with sweet taste, brown, navy blue and olive green go with bitter while grey and grey-blue colors are associated with salty taste.

The general requirements in terms of aesthetics are the harmony of colors, clear, distinct and strong tones that point out what is the most important.

Regarding the emotions that colors arouse, what is important for the package within this research is the psychological character, or in other words, the meaning of the color. 


\section{Research Methodology}

\section{Sample}

The authors of the paper carried out the analysis of the foodstuff product, the biscuit packets of different weights, whose packages bear some visual similarities (see Figure 3). The sample comprised 6 items of the same type of biscuit, wafers, produced by 6 different producers and which are available in the shops in Novi Sad (both in corner shops and mega markets).

Three groups of students of The Higher Technical School of Professional Education at Novi Sad were interviewed. The sample comprised 40 people. The first group included 20 students from the graphic design department. They were considered to be "qualified" respondents because they were familiar with the elements of package, marketing and the elements such as colour, text, illustration.

The second and the third group consisted of ten students of mechanical engineering and ten students of electrical engineering respectively. They were considered to be representatives of regular consumers.

The principle of choosing the respondents was that they belong to the same population of consumers who live in the same geographical area, they are of the same age, of different gender but they have similar interests and financial status.

A questionnaire was made according to the Picture 2 and the students were asked to complete it. The complete list of questions can be found in the Appendix.

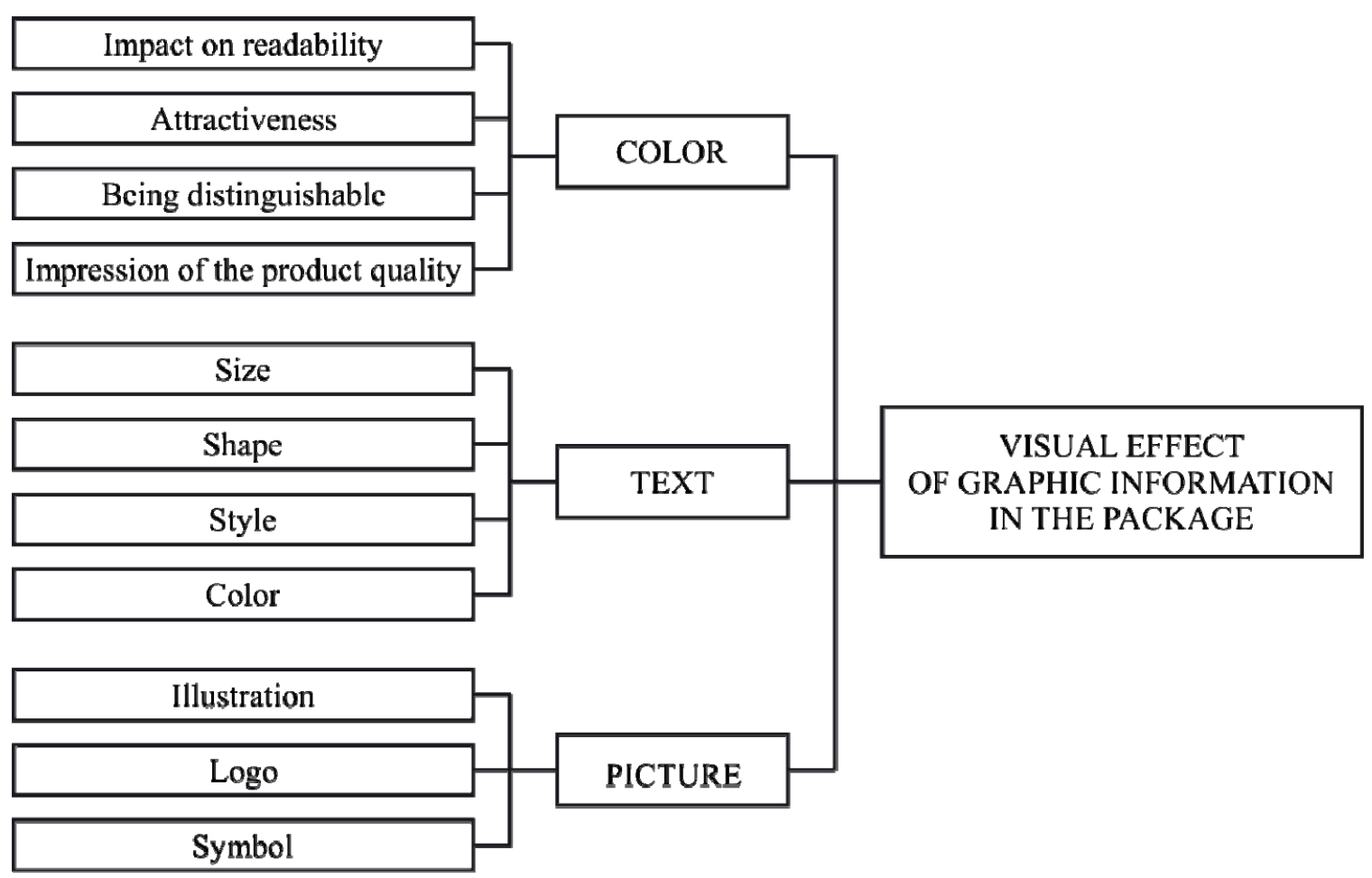

Figure 2. Communicative importance of the visual effect of graphic information in the package 


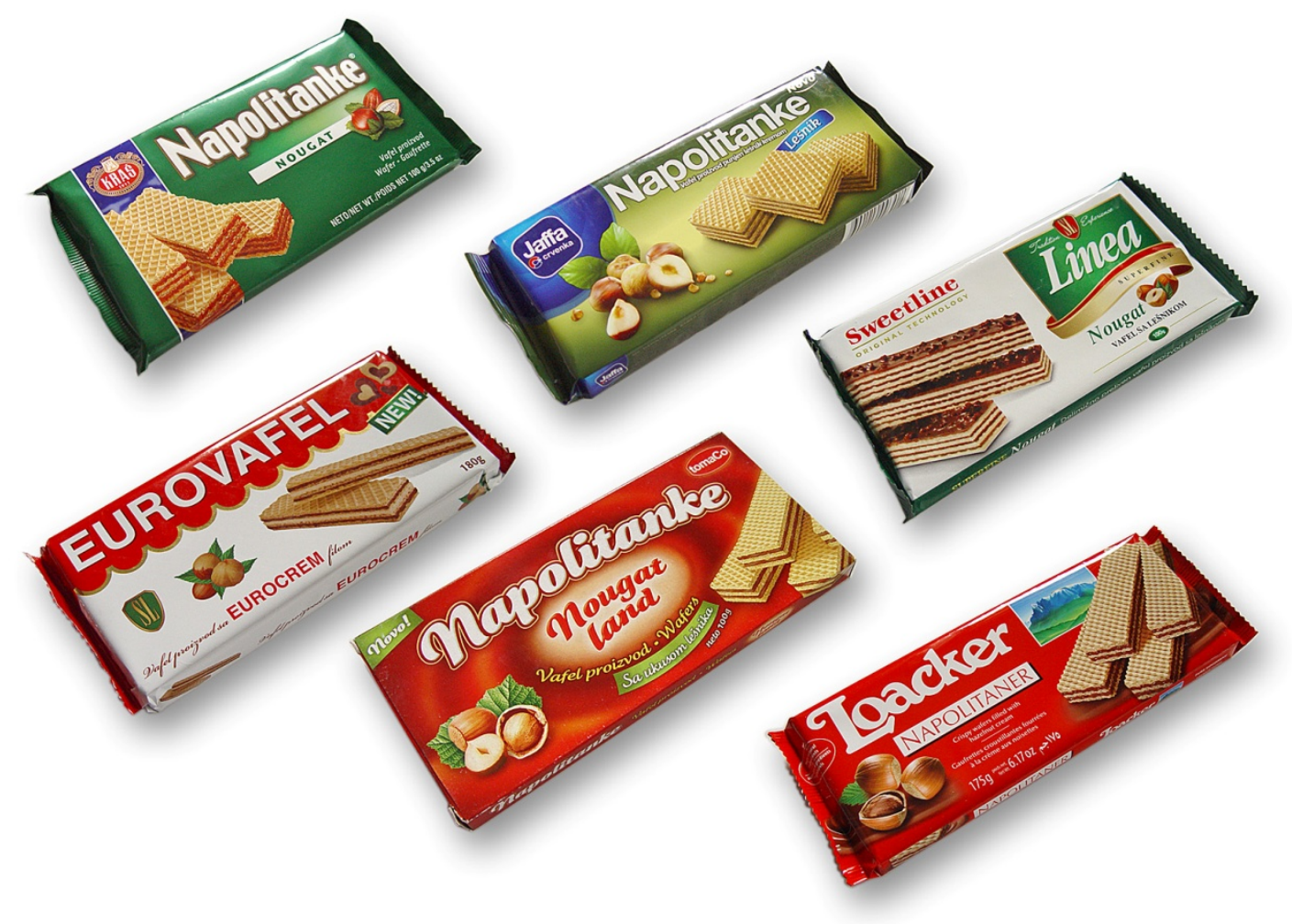

Figure 3. The samples of the package used in the research

\section{Results Analysis}

The survey of the students of graphic design is graphically represented in Figures 4-10.

Which product would you buy judging by the package?

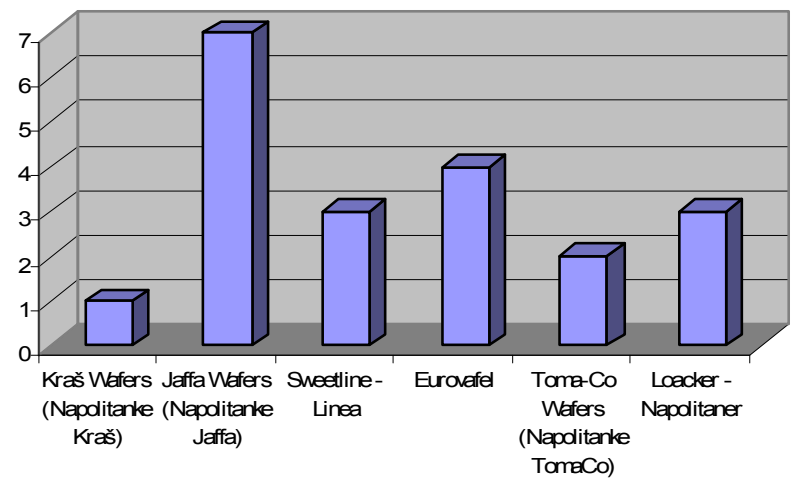

Figure 4: Results of the first answer of the questionnaire 
Do you notice the visual information in the package? Text

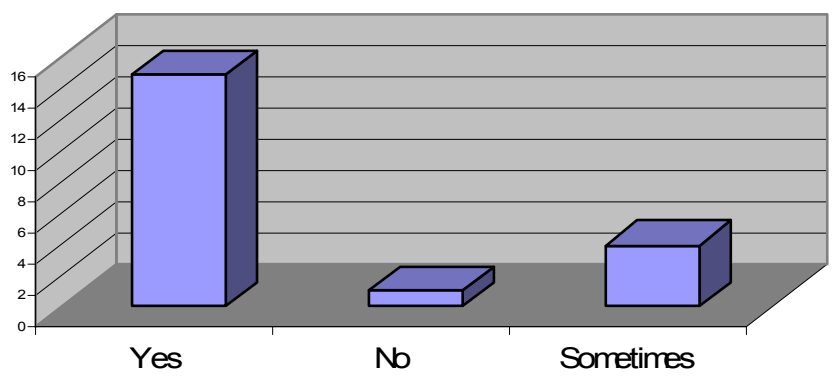

a)

\section{Do you notice the visual information in the package? Picture}

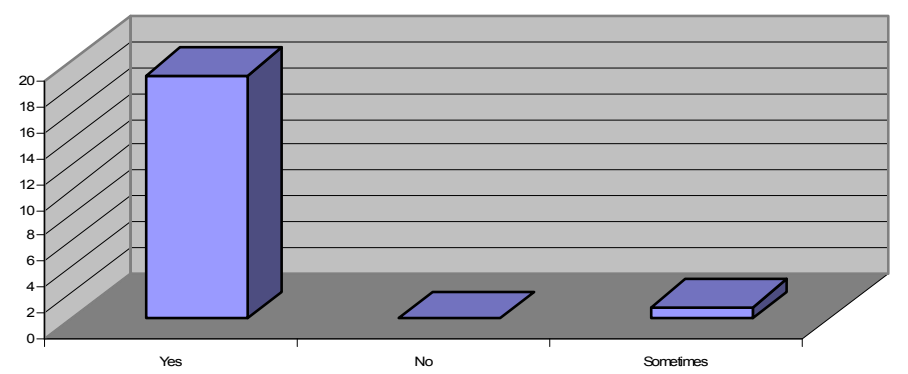

b)

\section{Do you notice the visual information in the package? Color}

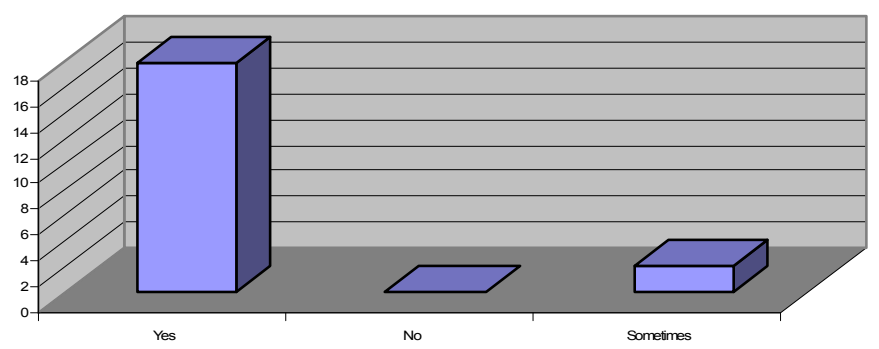

c)

Figure 5: Results of the second answer of the questionnaire 
Which of the pictorial information you notices immediately in the presented package?

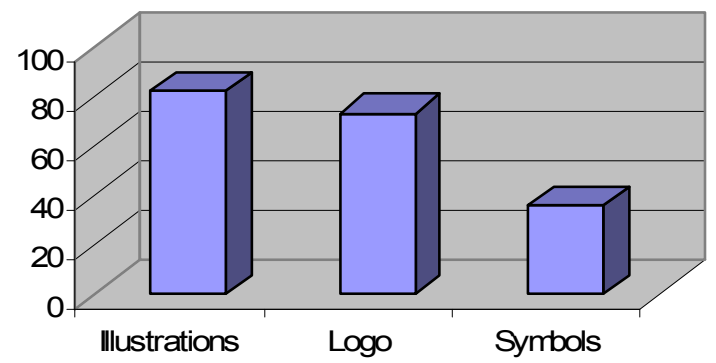

Figure 6: Results of the third answer of the questionnaire

Which color in the package attracts your attention most?

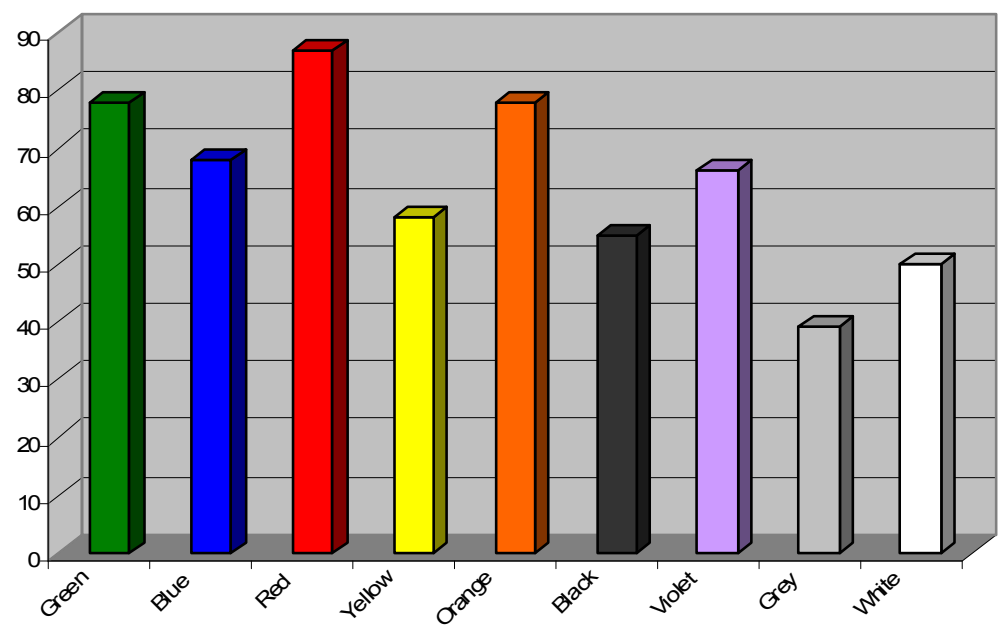

Figure 7: Results of the fourth answer of the questionnaire

The readability of the text is influenced by

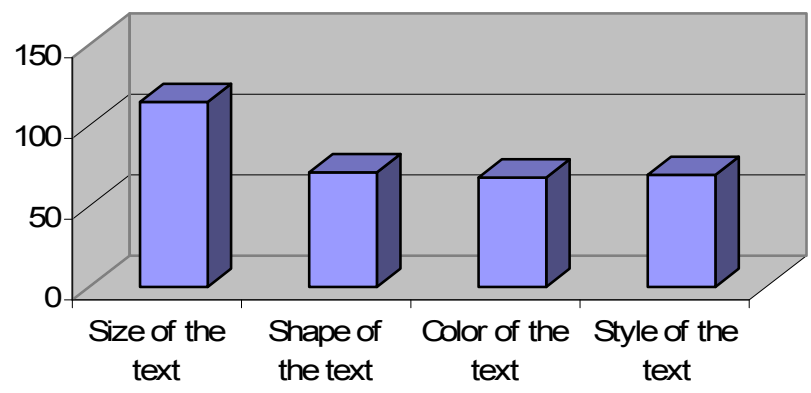

Figure 8: Results of the fifth answer of the questionnaire 
Colors in the package?

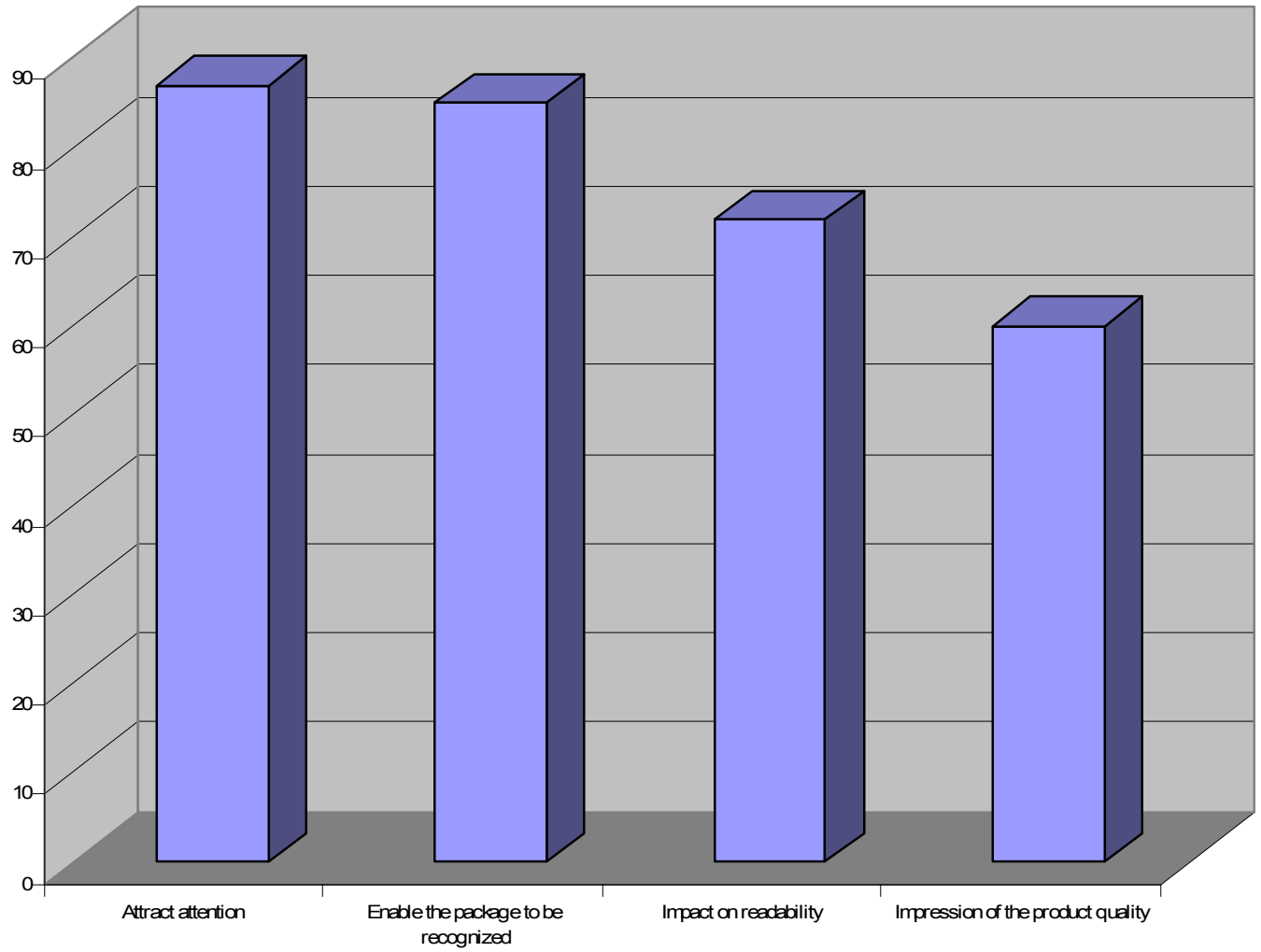

Figure 9: Results of the sixth answer of the questionnaire

Which of the mentioned visual information motivates you most to buy the packaged product?

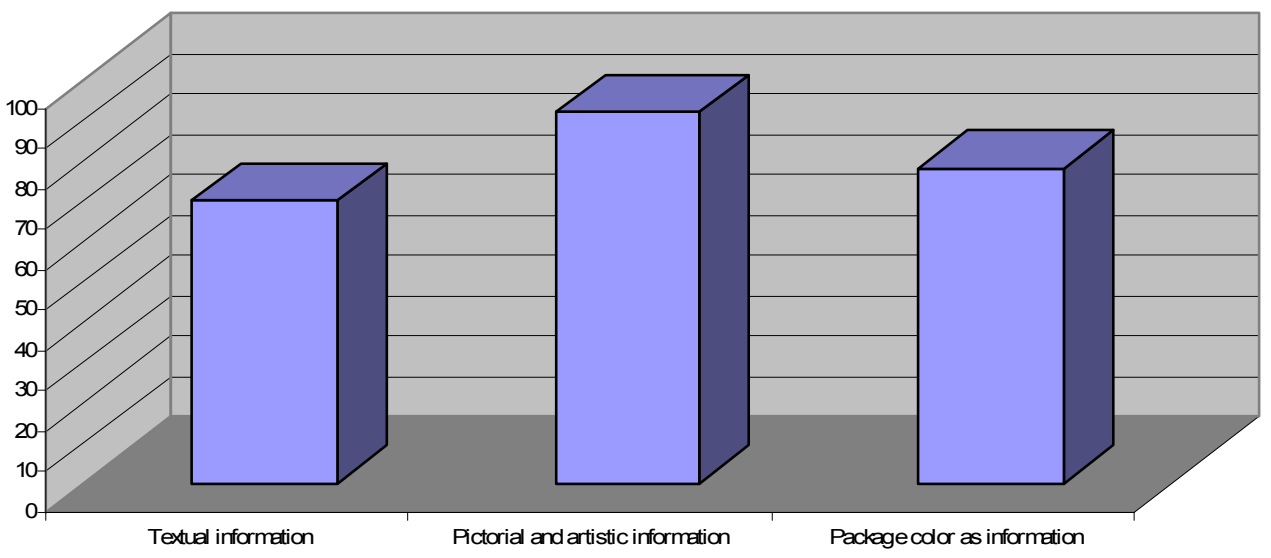

Figure 10: Results of the seventh answer of the questionnaire 
The survey of the students of graphic design provided the following results:

1. $35 \%$ of the respondents chose "Jaffa" wafers, $20 \%$ chose Eurovafel, $15 \%$ were in favor of "Sweetline-Linea" and "Loacker-Napolitaner", $10 \%$ chose "Toma-Co" wafers while 5 $\%$ of the respondents chose "Kraš" wafers.

2. Regarding the visual information in the package, the element that is the most noticeable is the picture (firstly, the respondents notice the illustration, then a logo and lastly the symbol), then colors and finally the text.

3. The readability of the text is influenced by the text size at most, then by the shape, while the text color and text style are equally important.

4. The respondents' attention is attracted by the following colors (from most to least): red, orange, green, blue, violet, yellow, black, white and grey.

5. The aim of the colors in the package is to draw the viewer's attention to the product and to help the product be recognizable. They have a smaller effect on the readability of the text and on our opinion regarding the product quality.

6. Finally, the best motivation for buying the product is provided by pictorial and artistic information, then by color and lastly by the text.

\section{The Comparative Analysis of the Survey}

Upon conducting of the survey, each group of samples was analyzed and the obtained results were different. The difference is obvious in two questions.

The first question where the difference in answers is evident is question number 2 - "Do you notice visual information in the package?"

Table 1 shows the results of this question in percentage and in Figure 11 are the results of the comparative analysis graphically represented.

Table 1: "Do you notice visual information in the package?"

\begin{tabular}{|c|c|c|c|c|}
\hline & & graphic design & mechanical engineering & electrical engineering \\
\hline \multirow[t]{3}{*}{ Text } & Yes & 75 & 40 & 100 \\
\hline & No & 5 & 20 & 0 \\
\hline & Sometimes & 20 & 20 & 0 \\
\hline \multirow[t]{3}{*}{ Picture } & Yes & 95 & 75 & 100 \\
\hline & No & 0 & 12.5 & 0 \\
\hline & Sometimes & 5 & 12.5 & 0 \\
\hline \multirow[t]{3}{*}{ Colour } & Yes & 90 & 77 & 100 \\
\hline & No & 0 & 11.1 & 0 \\
\hline & Sometimes & 10 & 11.1 & 0 \\
\hline
\end{tabular}

All three groups of the subjects answered in the affirmative (the first offered answer "Yes") to the question regarding whether they notice the "text", "picture" and "colour" as visual elements when choosing a product. However, with detailed analysis, it can be concluded that students of graphic design will be mostly influenced by the "picture" as a visual element. "Colour" will be the element which would attract students of mechanical engineering, whereas the students of electrical engineering chose all three answers, so we can conclude that all three elements "text", "picture" and "colour" equally influence their choice of a product. 


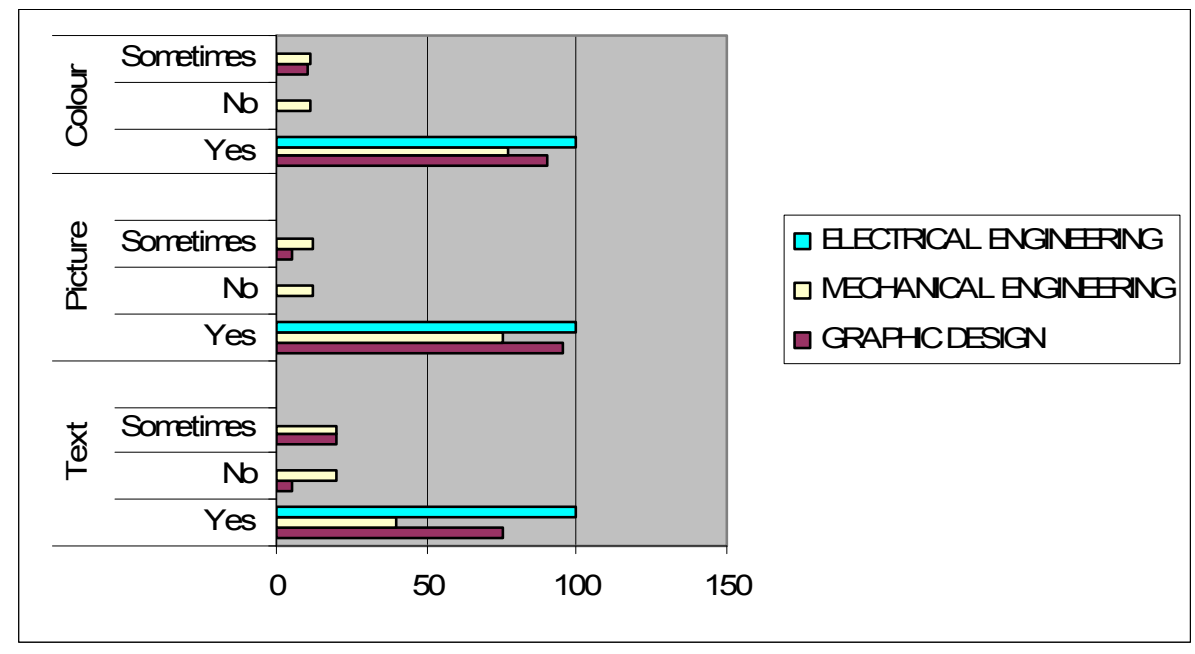

Figure 11: Results of the comparative analysis

The next question were the difference in answers is evident is question number 3 - "Which of the pictorial information did you notice first in the package?" The differences in answers to this question were more important.

Table 2 shows the results in percentage and in Figure 12 are the results of the comparative analysis graphically represented.

Table 2: Which of the pictorial information did you notice first in the package?

\begin{tabular}{|c|c|c|c|}
\hline & graphic design & mechanical engineering & electrical engineering \\
\hline Illustration & 42,93 & 39,5 & 32,71 \\
\hline Logo & 38,21 & 34,5 & 39,25 \\
\hline Symbol & 18,84 & 25,9 & 28,03 \\
\hline
\end{tabular}

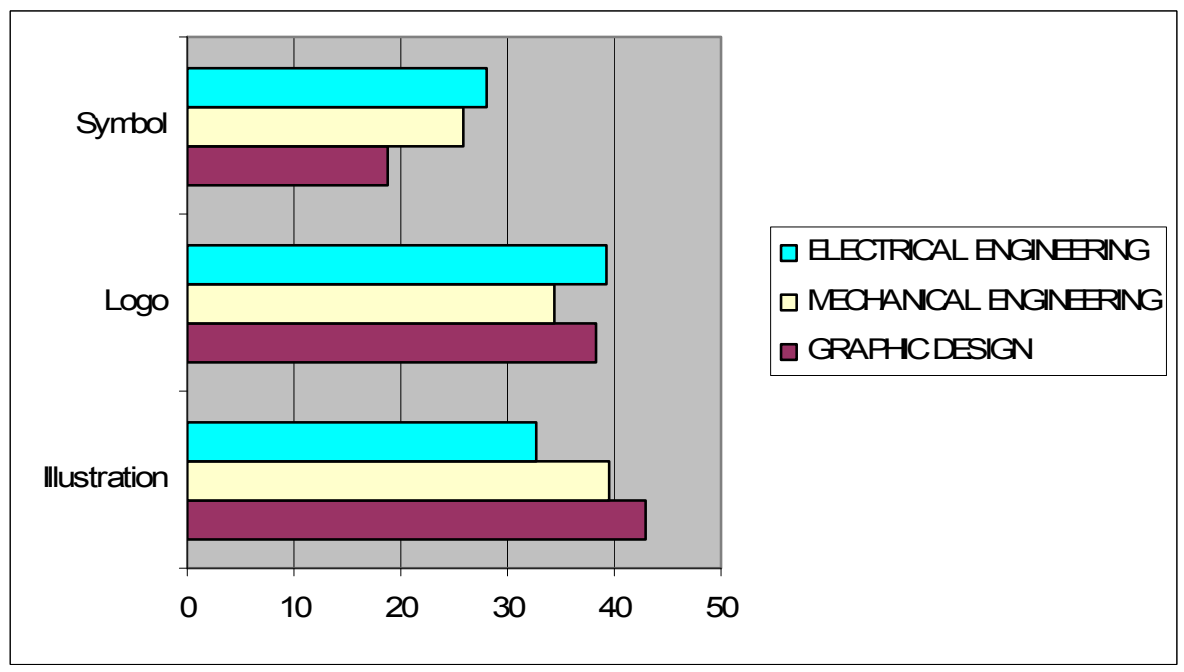

Figure 12: Results of the comparative analysis 
The analysis of the results showed that the students of graphic design and mechanical engineering are most influenced by illustration as a visual element, whereas the students of electrical engineering chose logo as the most significant element when purchasing a product.

\section{Conclusion}

The package in information and communication context aims to evoke the feeling of trust, care and affection in the consumer by the message which is made aesthetic to the extent that it satisfies the sense of beauty, taste and being practical.

From the consumer's point of view, the package is a tool that helps in choosing a product and deciding on a purchase, when the function of the package as information plays a prominent role.

In the attempt to answer the question regarding the degree to which a package influences the consumer in terms of the elements of the visual information it carries (text, picture and colour), we conducted a research (by interviewing target groups). The analysis of the questionnaire gave the following results:

- Visual information (text, picture and colour) is noticed in the package, but not equally. It depends on the target group. (The students of graphic design are mostly influenced by "picture" as a visual element. Colour is the element most likely to attract students of mechanical engineering, whereas the students of electrical engineering chose all three options and thus we can conclude that all three elements (text, picture and colour) are equally important to them.)

- Pictorial information (illustration, logo or symbol) also have different influence depending on the target group. (For the students of graphic design and mechanical engineering the most prominent visual element is "illustration" while the electrical engineering students opted for logo as the crucial element which would make them choose and buy a certain product.)

- Red colour draws attention of all three groups more than any other colour, while the order of other colours varies quite a lot.

- All three target groups think that the size of a text is important for the textual information to be legible. The order of other elements which influence the legibility (shape, color and text style) is different for all three target groups.

- All target groups agree that the colours in the package affect their attention, but they are the least important for their opinion about the quality of a product.

- The most influential element of visual information in the researched package is illustration (that is the opinion of all three target groups), then colour and lastly text (for the students of graphic design and mechanical engineering), whereas for the students of electrical engineering the second most influential information is text and then the colour.

This kind of research can help a graphic designer to develop uninhibited creativity and imagination and channel it into the right direction. Also, by applying these results a graphic designer would be able to exclude coincidence and arbitrariness in the final result to the maximum possible extent.

Further research into this topic would include a larger and a different target group, for example customers in a supermarket, a place where they shop. Also, it would include more precise questions (such as "Which textual information is the most important - price, date, expiry date etc.?"). 


\section{Appendix}

\section{Questionnaire: \\ Research Into the Impact of Visual Effect of Graphic Information in the Package}

1. Which product would you buy judging by the package?
a) Kraš Wafers (Napolitanke-Kraš)
b) Jaffa Wafers (Napolitanke-Jaffa)
c) Sweetline-Linea
d) Eurovafel
e) Toma-Co Wafers (Napolitanke TomaCo)
f) Loacker-Napolitaner

2. Do you notice the visual information in the package? (Yes / no / sometimes)
a) Text
b) Picture
c) Color

3. Which of the pictorial information you noticed immediately in the presented package? (Give a mark from 1 to 5)
b) Logo
c) Symbols
a) Green
b) Blue
c) Red
d) Yellow
e) Orange
f) Black
g) Violet
h) Grey
i) White

a) Illustrations

4. Which color in the package attracts your attention at most? (Give a mark from 1 to 5)

5. The readability of the text is influenced by (give a mark from 1 to 5):
a) Size of the text
b) Shape of the text
c) Color of the text
d) Style of the text
6. Colors in the package (give a mark from 1 to 5):
a) Attract attention
b) Enable the package to be recognized
c) Impact on readability
d) Impression of the product quality 
7. Which of the mentioned visual information motivates you most to buy the packaged product? (Give a mark from 1 to 5)

a) Textual information

b) Pictorial and artistic information

c) Package color as information

\section{References}

Bihler, J. (2005). Was macht Verpackungen packend? ProCarton Deutschland.

Drew, J., \& Meyer, S. (2008). Color management for packaging. Rotovision.

Fruht, M. (1995). Dizajn, od zanata preko umetnosti do nauke, Beograd.

Fruht, M., Rakić, M., \& Rakić, I. (1992). Grafički dizajn, kreacija za tržište, Zavod za udžbenike i nastavna sredstva, Beograd.

Hembree, R. (2008). Kompletan grafički dizajn, Don Vas.

Jurečić, D. (2004). Evaluacija elemenata vizualne informacije na grafičkoj opremi ambalaže, Magistarski rad: Sveučilište u Zagrebu, Fakultet organizacije i informatike Varaždin.

Perović, N.(2001). Ambalaža kao faktor konkurentnosti jugoslovenskog izvoza, Magistarski rad, Univerzitet u Novom Sadu, Ekonomski fakultet Subotica.

Reis, B. (2009). Komunikationsvielfalt oder Kommunikationseinfalt von Verpackungen, Diplomarbeit: Universitaet Wien.

Wang, R. W. Y., \& Chen, W-C. (2007). The study on packaging illustration affect on buying emotion, International Association of societies of Design research, The Hong Kong Polytechnic University.

\section{Biographies}

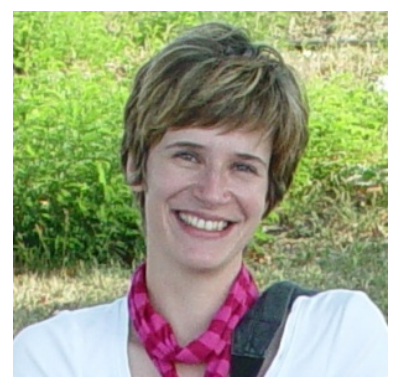

Petra Balaban-Đurđev, born 1975, is a lecturer at the Higher Technical School of Professional Education, Novi Sad, Serbia. She teaches Packaging design course and Postpress course. She holds a MS in Graphic Engineering and Design at Faculty of Tecnical Sciences, University of Novi Sad and is currently working towards her $\mathrm{PhD}$ at the same Faculty in the field of printing and multiciteria evaluation of packaging.

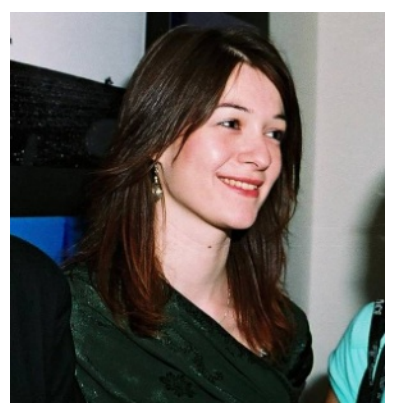

Varvara Maletić, born 1979, is a Marketing and Communication Manager at the Higher Technical School of Professional Education, Novi Sad, Serbia. She teaches Business Communications as a part of Sociology And Business Communications course. Currently working towards her MSc at Faculty of political science, University of Belgrade, Serbia, at field Communicology and Journalism. Has international papers at topics: regulation of communication, new media, television, e-government, e-democracy... 